\title{
Laparoscopic ovarian transposition before pelvic radiation in rectal cancer patient: safety and feasibility
}

\author{
Sami Al-Asari ${ }^{*}$ and Alaa Abduljabbar
}

\begin{abstract}
Background: Infertility due to pelvic radiation for advanced rectal cancer treatment is a major concern particularly in young patients. Pre-radiation laparoscopic ovarian transposition may offer preservation of ovarian function during the treatment however its use is limited.

Aim: The study investigates the safety, feasibility and effectiveness of pre-radiation laparoscopic ovarian transposition and its effect on ovarian function in the treatment o locally advanced rectal cancer.

Methods: Charts review of all young female patients diagnosed with locally advanced rectal cancer, underwent laparoscopic ovarian transposition, then received preoperative radiotherapy at king Faisal Specialist Hospital and Research Centre between 2003-2007.

Results: During the period studied three single patients age between 21-27 years underwent pre-radiation laparoscopic ovarian transposition for advanced rectal cancer. All required pretreatment laparoscopic diversion stoma due to rectal stricture secondary to tumor that was performed at the same time. One patient died of metastatic disease during treatment. The ovarian hormonal levels (FSH and LH) were normal in two patients. One has had normal menstrual period and other had amenorrhoea after 4 months follow-up however her ovarian hormonal level were within normal limits.
\end{abstract}

Conclusions: Laparoscopic ovarian transposition before pelvic radiation in advanced rectal cancer treatment is an effective and feasible way of preservation of ovarian function in young patients at risk of radiotherapy induced ovarian failure. However, this procedure is still under used and it is advisable to discuss and propose it to suitable patients.

Keywords: Laparoscopic, Ovarian, Transposition, Rectal cancer

\section{Introduction}

Colorectal cancer is the third most common cancer in the world and has significant mortality. Rectal cancer is usually staged with modalities such as endorectal ultrasound, Magnetic Resonance Imaging (MRI) and Computed Tomography (CT) of chest abdomen and pelvic.

Neoadjuvant chemo-radiation therapy is used routinely in low-lying rectal tumor to reduced local and systemic recurrence, improve respectability and attempt sphincter preservation $[1,2]$.

* Correspondence: sss_allah@hotmail.com

Department of colorectal surgery, King Faisal Specialist Hospital and Research Centre, Riyadh, Saudi Arabia
Pelvic radiation and chemotherapy particularly in the young female may cause infertility. Preservation of ovarian function by transposition of ovaries before pelvic radiation has been suggested in all reproductive women [3]. This procedure has been frequently offer to patients with advanced cervical cancer and Hodgkin's lymphoma having chemo-radiotherapy but less popular in advanced rectal cancer.

The estimated dose of radiation at which half of the follicles are lost in humans (LD50) is 4Grays [4]. Women less than 40 years old are less sensitive to radiation induced ovarian injury. However permanent ovarian failure will occur on exposure of 20Grays or over of pelvic radiation while old patients only require 6 Grays 
for ovarian failure [5]. In the ovarian transposition procedure both ovaries relocate temporally away from the direct radiation area. The ovarian transposition will prevent direct radiation induced injury to gynecological apparatus and helps in prevention of premature menopause. Although the procedure is well established as part of treatment in other malignancies little is known about its safety and feasibility in advanced rectal cancer.

\section{Aim}

The study investigates the safety, feasibility and effectiveness of pre-radiation laparoscopic ovarian transposition and its effect on ovarian function in the treatment of locally advanced rectal cancer.

\section{Methods}

Retrospective data were collected of all three patients underwent laparoscopic ovarian transposition before

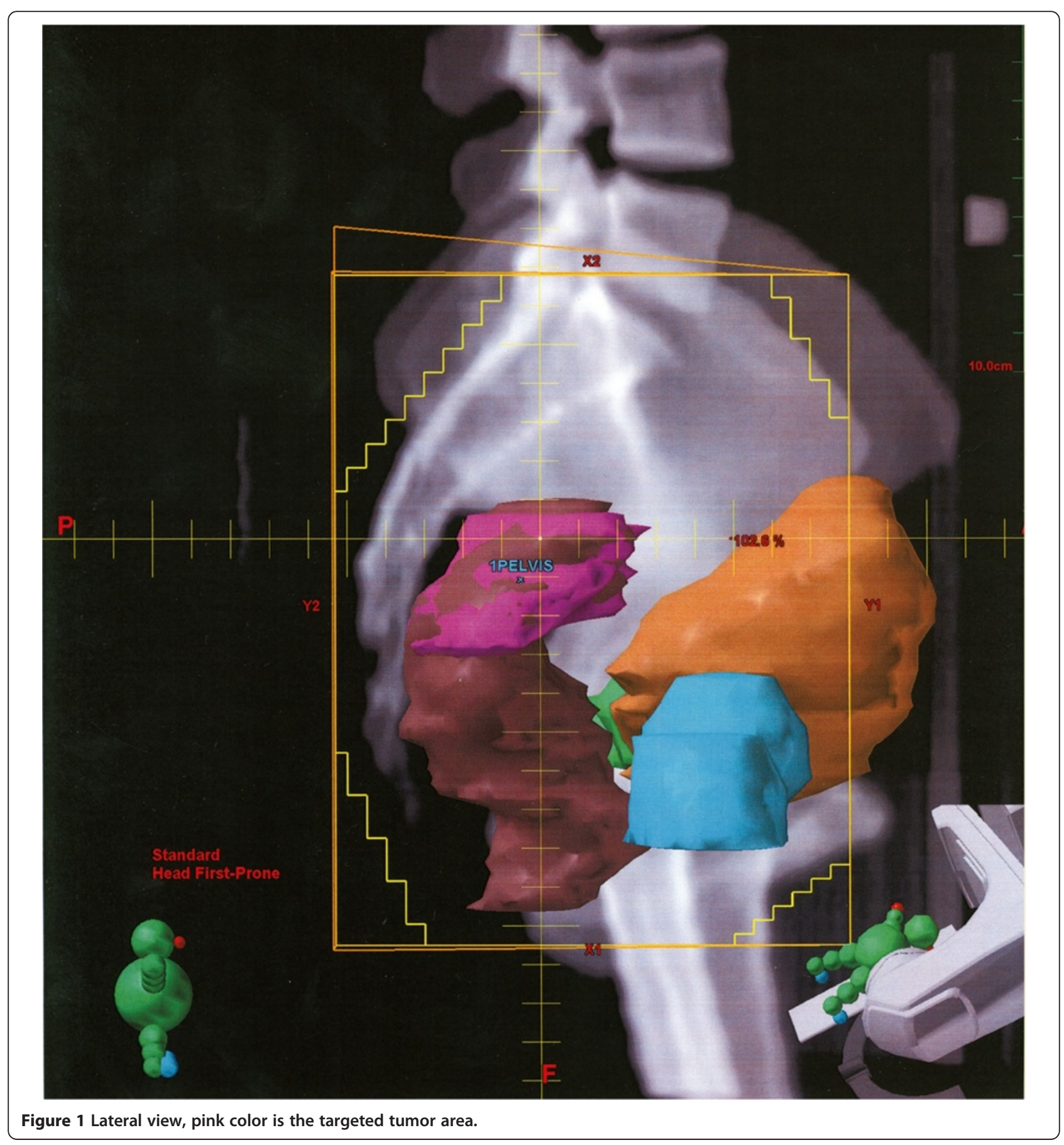


long course chemo-radiotherapy for locally advanced rectal cancer. The procedures were carried out at King Faisal Specialist Hospital and Research Centre in Saudi Arabia during 2003 to 2007.

A detailed history was taken from all three patients including their menstruation cycle and previous gynecological treatment. Blood were taken for hematological and biochemical makers including Follicle stimulating hormone (FSH) and Luteinising hormone (LH). All blood markers were measure before treatment and at 1, 2,4 and 6 months post-treatment.

Technically, we perform the ovarian transposition using minimal access approach in all three cases. The procedures were carried out under general anesthesia and a Foley's catheter was placed to empty the bladder. The patient was placed in Trendelenburg's position and a $12 \mathrm{~mm}$

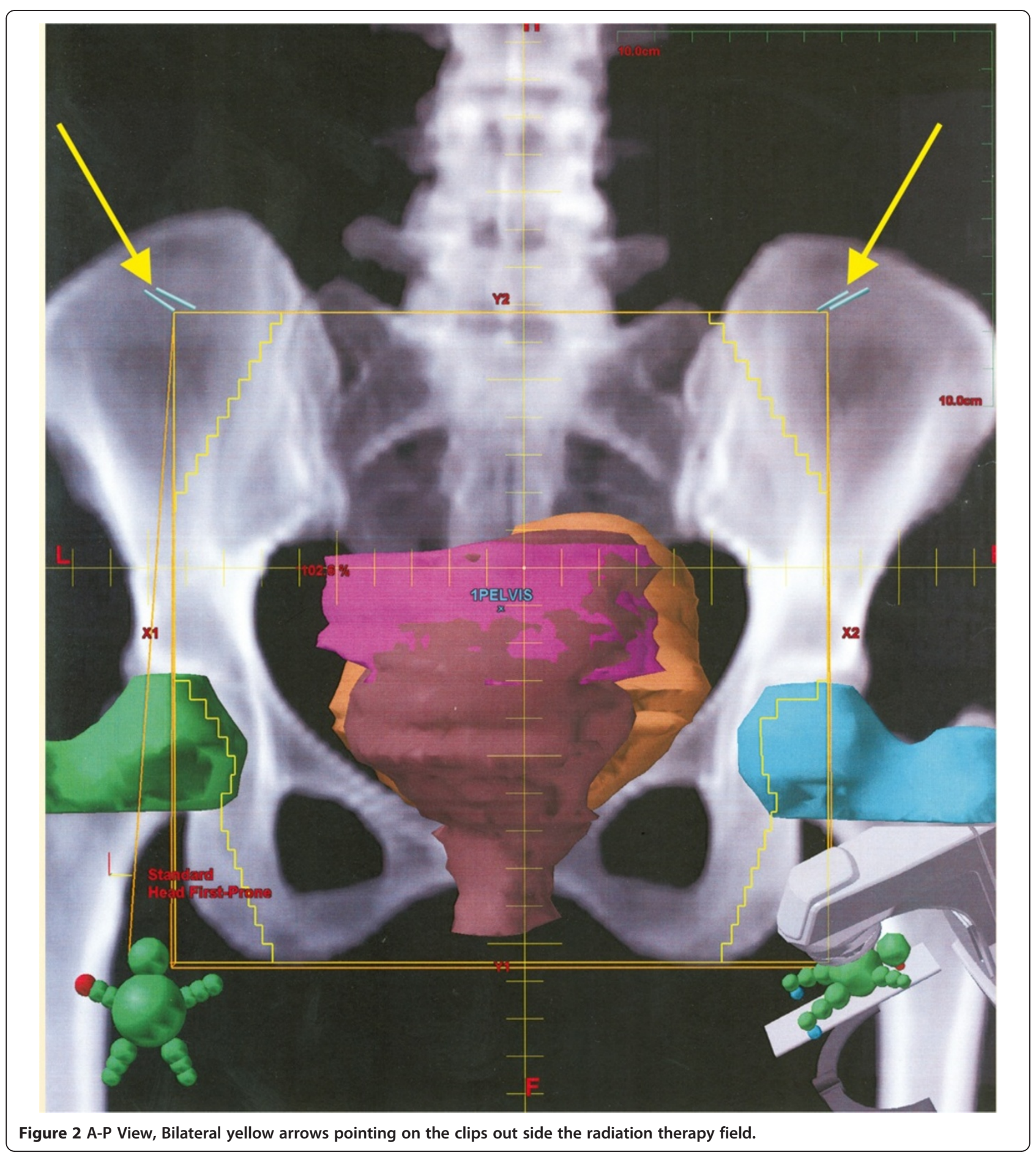


umbilical port inserted for abdominal cavity access using open technique. Insufflation was achieved using carbon dioxide $(\mathrm{CO} 2)$ gas and abdominal pressure of $12 \mathrm{~mm}$ of $\mathrm{Hg}$ was maintained during the procedure. A $5 \mathrm{~mm}$ port was inserted under vision in right and another one at left lumber region. The umbilical port was used for the $10 \mathrm{~mm} 300$ angled camera and $5 \mathrm{~mm}$ ports used as working ports. A diagnostic laparoscopy was performed to assess the tumor stage. Then, the peritoneum over pelvic sidewall was mobilized to develop a retroperitoneal space. All major vasculature (common, external and internal Iliac) structure were identified and preserved. The ovarian vessels and both ureters were exposed along its whole length. A Harmonic scalpel used to dissect the uteroovarian ligaments. The ovarian vessel was carefully mobilized to make sure the blood supply to the structure was not compromised. Both ovaries and fallopian tubes were fixed at the lateral abdominal wall below the spleen on

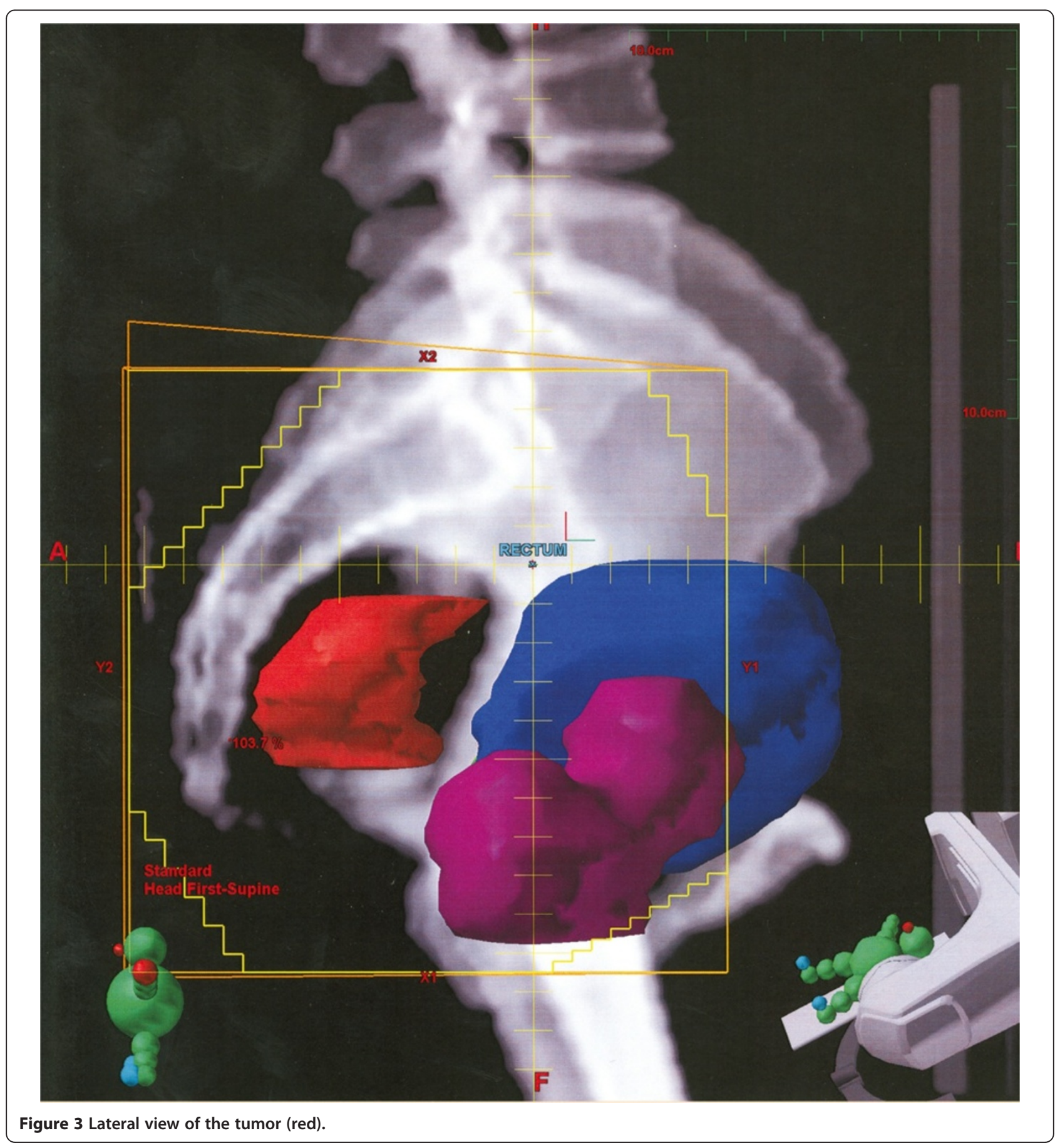


the left and liver on the right using Titanium based tuckers (ProTacks). A $5 \mathrm{~mm}$ metallic clip was placed at the base of both ovaries as a marker.

The pre-radiation film confirmed the metallic clip outside the area of pelvic radiation in all cases. A laparoscopic diversion transverse colostomy was created at the pre-marked site at right side of abdomen to prevent complete large bowel obstruction during the rectal cancer treatment. Simulation of radiation therapy and the position of the clips demonstrated on (Figures 1,2,3, and 4).

\section{Results}

We record 3 patients with age between 21-27 diagnosed with CT scan, MRI, Endorectal US, and colonoscopy to have a moderate differentiated rectal adenocarcinoma 4-10 cm from anal verge with compromised lumen. All of them underwent laparoscopic ovarian transposition

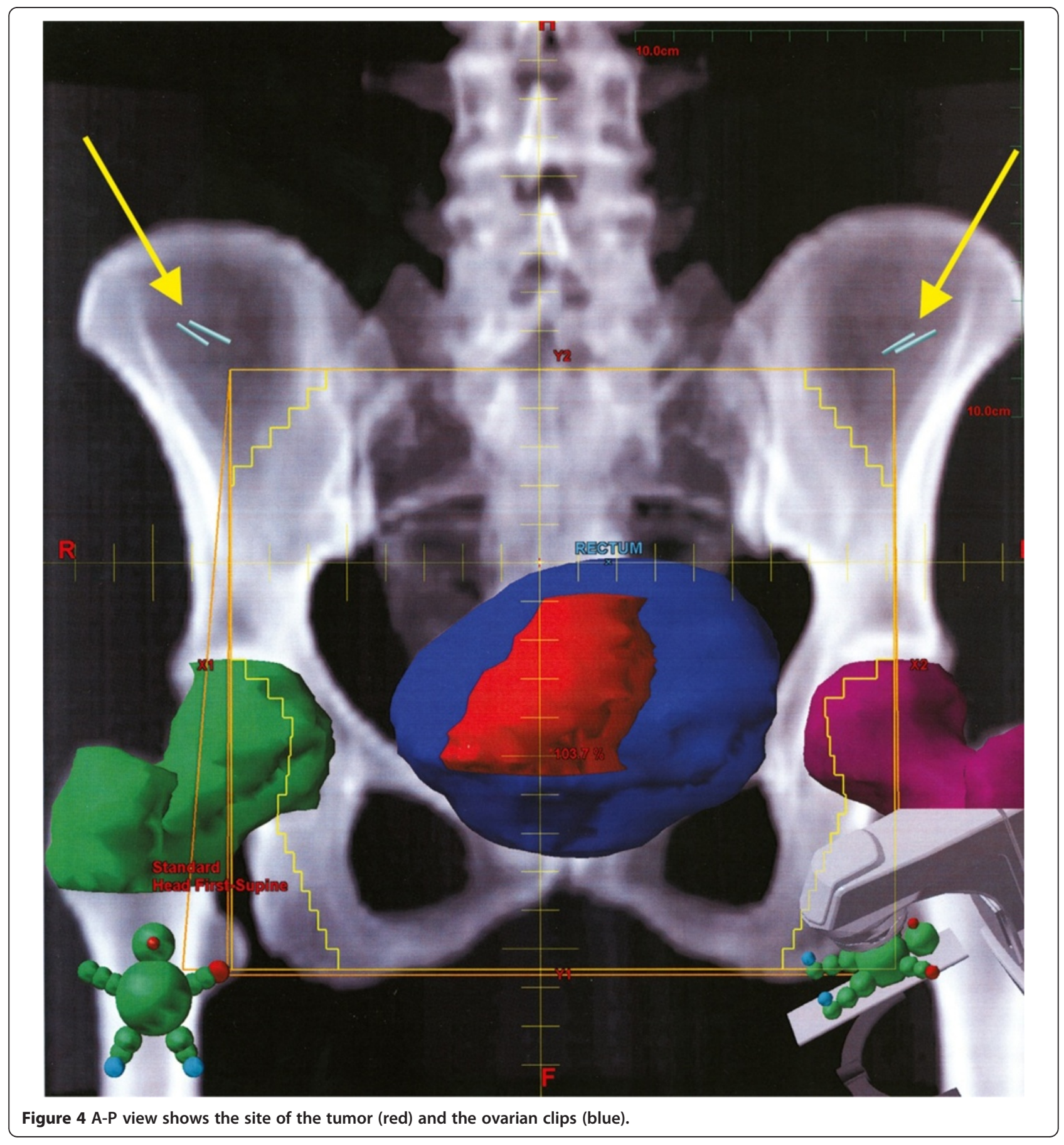


Table 1 Literature review of cervical and anorectal cancer

\begin{tabular}{|c|c|c|c|c|}
\hline Reference & Number & Treatment & $\begin{array}{l}\text { Proportion of patients with } \\
\text { preserved ovarian function }\end{array}$ & Follow-up (Months) \\
\hline Leonard A Farber [3] & 1 & Radiotherapy + LOT+LAR & $100 \%$ & 13 \\
\hline Hodel et al. [7] & 9 & $\mathrm{RH}+\mathrm{LOT} \pm X \mathrm{RT}$ & $78 \%$ & Ns \\
\hline \multirow[t]{3}{*}{ Husseinzadeh et al. [8] } & 22 & $\mathrm{RH}+\mathrm{LOT}$ & $100 \%$ & Ns \\
\hline & 14 & LOT+XRT & $67 \%$ & \\
\hline & 4 & $\mathrm{RH}+\mathrm{LOT}+\mathrm{XRT}$ & $50 \%$ & \\
\hline \multirow[t]{2}{*}{ Chambers et al. [9] } & 54 & $\mathrm{RH}$ & $96 \%$ & 54(median) \\
\hline & 25 & $\mathrm{RH}+\mathrm{LOT}$ & $96 \%$ & 36(median) \\
\hline Chambers et al. [10] & 14 & RH+LOT+ Radiotherapy & $71 \%$ & 35(median) \\
\hline \multirow[t]{3}{*}{ Feeney et al. [11] } & 58 & $\mathrm{RH}+\mathrm{BSO} \pm \mathrm{XRT}$ & $0 \%$ & 24(mean) \\
\hline & 104 & $\mathrm{RH}+\mathrm{LOT}$ & $97 \%$ & \\
\hline & 28 & $\mathrm{RH}+\mathrm{LOT}+\mathrm{XRT}$ & $50 \%$ & \\
\hline Covens et al. [12] & 3 & PLND+LOT+XRT & $66 \%$ & $25-32$ \\
\hline \multirow[t]{2}{*}{ Van Eijkeren et al. [13] } & 36 & $\mathrm{RH}+\mathrm{LOT}$ & $95 \%$ & $36-48$ \\
\hline & 18 & $\mathrm{RH}+\mathrm{LOT}+\mathrm{XRT}$ & $72 \%$ & \\
\hline \multirow[t]{3}{*}{ Morice et al. [14] } & 11 & $\mathrm{RH}+\mathrm{LOT}$ & $100 \%$ & 31 (median) \\
\hline & 59 & RH+LOT+Brachy & $90 \%$ & \\
\hline & 35 & RH+LOT+XRT+Brachy & $60 \%$ & \\
\hline \multirow[t]{2}{*}{ Yamamoto et al. [15] } & 30 & $\mathrm{RH}+\mathrm{LOT}$ & $97 / 89 \%$ & At 12 v.s. At 60 \\
\hline & 26 & $\mathrm{RH}+\mathrm{LOT}+\mathrm{XRT}$ & $65 / 39 \%$ & \\
\hline Buekers et al. [16] & 17 & Radiotherapy + LOT \pm RH & $41 \%$ & At 12 \\
\hline Treissman MJ et al. [17] & 1 & Radiotherapy +LOT & $50 \%$ & 8 \\
\hline
\end{tabular}

$\mathrm{RH}$ radical hysterectomy, LOT lateral ovarian transposition, XRT external beam radiotherapy, BSO bilateral salpingo-oophorectomy, PLND pelvic lymph node dissection only, Brachy brachytherapy, Ns not stated.

and diverting colostomy. Postoperatively they received long course chemoradiation. All patients are single. The hormonal level were measured at 1,2,4 and 6 months and we found that the FSH range between $(2-79.9 \mathrm{Iu} / \mathrm{L})$ and $\mathrm{LH}(3.7-36.2 \mathrm{Iu} / \mathrm{L})$ which is within normal limit. There were no postoperative surgical related complications. On follow up, one patient died form neutropenic bowel perforation and sepsis and we found that she have liver metastasis during therapy, while the other tow maintain their menstruation with delay in one of them for four months.

\section{Discussion}

Our study investigated the safety and feasibility of the laparoscopic ovarian transposition before pelvic radiation in advanced rectal cancer treatment. This is usually measured by quantitative analysis of ovarian hormones as well as fertility outcome [3].

Spontaneous pregnancies are possible if tubal function is preserved as part of the ovarian transposition and fixation [3].

Morice et al. [5] reported on 37 consecutive cases of ovarian transposition procedures. In his study 16 patients become pregnant spontaneously 12 of which did not have the ovaries repositioned from the adnexa. Similarly,
Dabirashrafi et al. have reported intrauterine pregnancy after laparoscopic ovarian transposition in another study [6].

Young patients require long course chemo-radiotherapy for advanced rectal cancer should be offer laparoscopic ovarian transposition before the radiation in which preservation of ovarian function is desired. We believe that placement of metallic clips at the base of ovaries as maker help the radiotherapist to identify this structure before radiation. The laparoscopic ovarian transposition preserved the ovarian hormonal function after the rectal cancer treatment in our patients. However none of them so far conceive, therefore impact of the procedure on fertility requires longer follow-up.

The laparoscopic procedure has been reported for different pelvic pathology and achieves almost a comparable successes rate.

Literature review for the cervical and anorectal cancer cases were they had the same procedure with different success rate and the length of the follow up summarized in Table 1 . The infertility has a major impact on the quality of life of young female patients with advanced rectal cancer after treatment. Our study suggests that laparoscopic ovarian transposition is safe, effective and feasible in preservation of ovarian hormonal function 
during and after the pelvic radiation therapy in advanced rectal cancer patients. However, further studies are required to assess its role in ovarian preservation and fertility before it could be widely used.

\section{Competing interest}

The authors declare that they have no competing interests.

\section{Authors' contribution}

SA-A: Data collection, analysis and writing the manuscript. AA: Data

collection and manuscript revision. Both authors read and approved the final manuscript.

\section{Funding}

The funding for this article belong the author SAMI ALASARI.

Received: 2 November 2011 Accepted: 19 July 2012

Published: 17 September 2012

\section{References}

1. Minsky BD, Cohen AM, Enker WE: Preoperative 5-FU, low dose leucovorin, and concurrent radiation therapy for rectal cancer. Int J Radiat Oncol Biol Phys 15 January 1997, 37(2):289-295.

2. Bosset JF, Pavy JJ, Hamers HP: Determination of the optimal dose of 5-fluorouracil when combined with low dose D. L-leucovorin and irradiation in rectal cancer. Results of three consecutive phase II studies. Eur I Cancer 1993, 29:476.

3. Farber LA, Ames JW, Rush S, Gal D: Laparoscopic Ovarian Transposition to Preserve Ovarian Function Before Pelvic Radiation and Chemotherapy in a Young Patient With Rectal Cancer. MedGenMed 2005, 7(1):66.

4. Wallace WH, Shalet SM, Tetlow LJ, Morris-Jones PH: Ovarian function following the treatment of childhood acute lymphoplastic leukaemia. Med Pad. Oncol. 1993, 21:33-339.

5. Morice $P$, Thiam-Ba $R$, Castaine $D$ : Fertility results after ovarian transposition for pelvic malignancies treated by external irradiation or brachytherapy. Hum Reprod 1998, 13:660-663.

6. Dabirashrafi H, Moghadami-Tabrizi N, Zandinejad K: Laparoscopic ovarian transposition with subsequent intrauterine pregnancy. J Am Assoc Gynecol Laparosc 1996, 3:515-517.

7. Hodel K, Rich WM, Austin P: The role of ovarian transposition in conservation of ovarian function in radical hysterectomy followed by pelvic radiation. Gynecol Oncol 1982, 13:195

8. Husseinzadeh N, Nahhas WA, Velkley DE: The preservation of ovarian function in young women undergoing pelvic radiation therapy. Gynecol Oncol 1984, 18:373.

9. Chambers SK, Chambers JT, Holm C: Sequelae of lateral ovarian transposition in unirradiated cervical cancer patients. Gynecol Oncol 1990, 39:155.

10. Chambers SK, Chambers JT, Kier R: Sequelae of lateral ovarian transposition in irradiated cervical cancer patients. Int I Radiat Oncol Biol Phys 1991, 20:1305.

11. Feeney DD, Moore DH, Look KY: The fate of the ovaries after radical hysterectomy and ovarian transposition. Gynecol Oncol 1995, 56:3.

12. Covens AL, van der Putten HW, Fyles AW: Laparoscopic ovarian transposition. Eur J Gynaecol Oncol 1996, 17:177.

13. Van Eijkeren MA, Van DWI, El Sharouni SY: Benefits and side effects of lateral ovarian transposition performed during radical hysterectomy and pelvic lymphadenectomy for early stage cervical cancer. Int J Gynecol Cancer 1999, 9:396.

14. Morice $P$, Juncker $L$, Rey $A$ : Ovarian transposition for patients with cervical carcinoma treated by radiosurgical combination. Fertil Steril 2000, 74:743

15. Yamamoto R, Okamoto $K$, Yukiharu T: A study of risk factors for ovarian metastases in stage IB-IIIB cervical carcinoma and analysis of ovarian function after a transposition. Gynecol Oncol 2001, 82:312.

16. Buekers TE, Anderson B, Sorosky Jl: Ovarian function after surgical treatment for cervical cancer. Gynecol Oncol 2001, 80:85.

17. Treissman MJ, Miller D, McComb PF: Laparoscopic lateral ovarian transposition. Fertil Steril 1996, 65:1229-1231. doi:10.1186/1750-1164-6-9

Cite this article as: Al-Asari and Abduljabbar: Laparoscopic ovarian transposition before pelvic radiation in rectal cancer patient: safety and feasibility. Annals of Surgical Innovation and Research 2012 6:9.

\section{Submit your next manuscript to BioMed Central and take full advantage of:}

- Convenient online submission

- Thorough peer review

- No space constraints or color figure charges

- Immediate publication on acceptance

- Inclusion in PubMed, CAS, Scopus and Google Scholar

- Research which is freely available for redistribution 